\title{
The Link Between Atrial Fibrillation and Obesity
}

\author{
P Socié* and H Gorka \\ Hospital of Louis Pasteur, Chartres, France
}

*Corresponding author: P Socie, Hospital of Louis Pasteur, Chartres, France

Received: 阱 January 30, 2019

Published: 笽February 05, 2019

\section{Introduction}

The obese population is currently increasing. Atrial fibrillation (AF) is the most common supraventricular arrhythmia. There is a close link between these two pathologies that we will detail in this article.

\section{Epidemiology}

The World Health Organization estimates that cases of obesity have tripled since 1975 with $39 \%$ of overweight adults and $13 \%$ of obese adults in 2016. Obesity is an independent risk factor of $\mathrm{AF}$ and those in spite of other associated comorbidity (sleep apnea, arterial hypertension, physical inactivity, diabetes mellitus ...) [1-4] The increase in the body mass index (BMI) is associated with an increase in the incidence of AF. Conversely, the standardization of BMI is associated with a decrease in the incidence of AF. [2] It is estimated that one in five of AF may be due to being overweight or obesity [5].

\section{Physiopathology}

Structural remodeling (atrial enlargement, increased fat depots, interstitial fibrosis, increased of left ventricular geometric abnormalities, altered hemodynamics) is a major factor by which obesity promotes AF. [6] Associated with oxidative stress, these two mechanisms are the main cause of AF in the obese patient. We will not discuss the particular pathophysiology of diabetes that is often associated with obesity in this population. Atrial electrical remodeling is a cause and consequence of AF. At the tissue level, electrical remodeling comprises effective refractory period shortening, conduction velocity slowing, wavelength reduction, and frequent atrial ectopic caused by calcium $\left(\mathrm{Ca}^{2+}\right)$-dependent triggered activity $[7,8]$. While $\mathrm{Ca}^{2+-}$ mediated triggers serve as the critical initiators of AF, an appropriate substrate formed through progressive electrical and structural remodeling of the atria is required for the long-term perpetuation of the arrhythmia and its conversion from paroxysmal to chronic forms.
Pericardial fat volume which correlates with left atrial enlargement has been associated with increased risk of AF [9]. It expresses anti-inflammatory adipokines and pro-inflammatory cytokines (including interleukin (IL)-1 $\beta$, IL-6, IL-8, TNF- $\alpha$ ). Reversal of atrial fat by weight loss is associated with reduced AF burden [911]. Other complications of obesity also favor the occurrence of AF. The main ones are developed heart disease, arterial hypertension, coronary disease, sleep apnea, diabetes and metabolic syndromes [12].

\section{Management Issues Specific}

The management of atrial fibrillation in obese patients begins with the global management of obesity. The weight loss is directly related to the dimming of AF. The management of its complications, such as sleep apnea syndromes, the treatment of arterial hypertension, the management of diabetes, and the development of cardiopathy can reduce prevail and recurrence of the AF. The management of AF in obese patients has a peculiarity that we will highlight in the following paragraph.

\section{Special Feature of Anticoagulation}

Of all the molecules used in the AF of the obese, a lot of study data are missing and requires more documentation. The historical treatment with anti-vitamin $\mathrm{K}$ is particular in the obese patient. It has been proven that there is a need for a larger dose of warfarin (for example) and that delay between initiation of treatment and steady state takes longer. [13] With regard to the new direct oral anticoagulant, the data is limited.

For example, the FDA conducted an analysis that compared the rates of stroke and systemic embolism (SSE) among rivaroxaban and warfarin patients from ROCKET AF across 5 weight categories (<50 kg, 50- $\leq 70 \mathrm{~kg}, 70-\leq 90 \mathrm{~kg}, 90-\leq 110 \mathrm{~kg}$, and >100 kg). [14] There was no statistical relationship between weight category and the rate of SSE. There are no published pharmacokinetic or clinical 
analyses of dabigatran in patients with extreme weights extremes. A recent study on apixaban seems to show that, compared to warfarin in obese or overweight patients, there is less SSE without risk of bleeding [15].

\section{Heart Rhythm Control or Rate Control}

The difficulty of maintaining the heart rate under medical treatment is truer in this population. For example, it has been shown that clearance of amiodarone was significantly reduced in those with BMI $>25 \mathrm{~kg} / \mathrm{m}^{2}$. [16] Higher shock energy was needed for increased first-shock success when transthoracic direct current cardioversion was studied in overweight and obese individuals. [17] However, the ablation is less effective in the obese. An index $\mathrm{BMI} \geq 30 \mathrm{~kg} / \mathrm{m}^{2}$ led to a 1.2 -fold increased likelihood of experiencing recurrent $\mathrm{AF}$ at 12-months follow-up as compared with overweight patients (HR 1.223; 95\% CI 1.047 to 1.429; p=0.011), while no significant correlation was found between overweight and normal BMI groups (HR 0.954; 95\% CI 0.798 to 1.140; $\mathrm{p}=0.605$ ) and obese versus normal BMI (HR 1.16; 95\% CI 0.965 to 1.412; $\mathrm{p}=0.112$ ) [18].

The surgical approach seems interesting but remains to be confirmed. A meta- analysis of 6 studies of patients undergoing coronary artery bypass surgery suggested that posterior pericardiectomy significantly reduced the incidence of postoperative AF. [19] More recently, a study assessing injections of botulinum toxin into the epicardial fat pad reduced the recurrence rate of AF after cardiac surgery. [20] Ablation of atrial fibrillation alone by thoracotomy seems limited by the risk of surgery, especially by ventilatory problems. Obese patients undergoing rate control strategy were more likely to have higher and uncontrolled resting heart rate as compared with their leaner counterparts [21].

\section{Conclusion}

The management of $\mathrm{AF}$ in the obese patient is complex and justifies multidisciplinary and comprehensive management. The central point remains the prevention and early management of obesity.

\section{References}

1. Gami AS, Hodge DO, Herges RM, Olson EJ, Nykodym J, et al. (2007) Obstructive sleep apnea, obesity, and the risk of incident atrial fibrillation. Journal of the American College of Cardiology 49(5): 565571.

2. Knuiman M, Briffa T, Divitini M, Chew D, Eikelboom J, et al. (2014) A cohort study examination of established and emerging risk factors for atrial fibrillation: the Busselton Health Study. European journal of epidemiology 29(3): 181-190.

3. Tedrow UB, Conen D, Ridker PM, Cook NR, Koplan BA, et al. (2010) The long- and short-term impact of elevated body mass index on the risk of new atrial fibrillation the WHS (women's health study). Journal of the American College of Cardiology 55(21): 2319-2327.

4. Wang TJ, Parise H, Levy D, D’Agostino RB, Sr Wolf PA, et al. (2004) Obesity and the risk of new-onset atrial fibrillation. Jama 292(20): 2471-2477.

5. Huxley RR, Lopez FL, Folsom AR, Agarwal SK, Loehr LR, et al. (2011)
Absolute and attributable risks of atrial fibrillation in relation to optimal and borderline risk factors: the Atherosclerosis Risk in Communities (ARIC) study. Circulation. 123(14): 1501-1508.

6. Tadic M, Cuspidi C (2015) The influence of type 2 diabetes on left atrial remodeling. Clinical cardiology 38(1): 48-55.

7. Heijman J, Voigt N, Nattel S, Dobrev D (2014) Cellular and molecular electrophysiology of atrial fibrillation initiation, maintenance, and progression. Circulation research 114(9): 1483-1499.

8. Nattel S, Guasch E, Savelieva I, Cosio FG, Valverde I, et al. (2014) Early management of atrial fibrillation to prevent cardiovascular complications. European heart journal 35(22): 1448-1456.

9. Karam BS, Chavez Moreno A, Koh W, Akar JG, Akar FG (2017) Oxidative stress and inflammation as central mediators of atrial fibrillation in obesity and diabetes. Cardiovascular diabetology 16(1): 120

10. Mahabadi AA, Massaro JM, Rosito GA, Levy D, Murabito JM, et al. (2009) Association of pericardial fat, intrathoracic fat, and visceral abdominal fat with cardiovascular disease burden: the Framingham Heart Study. European heart journal 30(7): 850-856.

11. Mazurek T, Zhang L, Zalewski A, Mannion JD, Diehl JT, et al. (2003) Human epicardial adipose tissue is a source of inflammatory mediators. Circulation 108(20): 2460-2466.

12. Lavie CJ, Pandey A, Lau DH, Alpert MA, Sanders P (2017) Obesity and Atrial Fibrillation Prevalence, Pathogenesis, and Prognosis: Effects of Weight Loss and Exercise. Journal of the American College of Cardiology 70(16): 2022-2035.

13. Wallace JL, Reaves AB, Tolley EA, Oliphant CS, Hutchison L, et al. (2013) Comparison of initial warfarin response in obese patients versus nonobese patients. Journal of thrombosis and thrombolysis. 36(1): 96-101.

14. Buckley LF, Rybak E, Aldemerdash A, Cheng JW, Fanikos J (2017) Direct oral anticoagulants in patients with atrial fibrillation and renal impairment, extremes in weight, or advanced age. Clinical Cardiology 40(1): 46-52.

15. Sandhu RK, Ezekowitz JA, Hijazi Z, Westerbergh J, Aulin J, et al. (2018) Obesity paradox on outcome in atrial fibrillation maintained even considering the prognostic influence of biomarkers: insights from the ARISTOTLE trial. Open heart 5(2): e000908.

16. Fukuchi H, Nakashima M, Araki R, Komiya N, Hayano M, et al. (2009) Effect of obesity on serum amiodarone concentration in Japanese patients: population pharmacokinetic investigation by multiple trough screen analysis. Journal of clinical pharmacy and therapeutics 34(3): 329-336.

17. Glover BM, Walsh SJ, McCann CJ, Moore MJ, Manoharan G, et al. (2008) Biphasic energy selection for transthoracic cardioversion of atrial fibrillation. The BEST AF Trial. Heart (British Cardiac Society). 94(7): 884-887.

18. Glover BM, Hong KL, Dagres N, Arbelo E, Laroche C, et al. (2019) Impact of body mass index on the outcome of catheter ablation of atrial fibrillation. Heart (British Cardiac Society) 105(3): 244-250.

19. Biancari F, Mahar MA (2010) Meta-analysis of randomized trials on the efficacy of posterior pericardiotomy in preventing atrial fibrillation after coronary artery bypass surgery. The Journal of thoracic and cardiovascular surgery 139(5): 1158-1161.

20. Pokushalov E, Kozlov B, Romanov A, Strelnikov A, Bayramova S, et al. (2014) Botulinum toxin injection in epicardial fat pads can prevent recurrences of atrial fibrillation after cardiac surgery: results of a randomized pilot study. Journal of the American College of Cardiology 64(6): 628-629.

21. Ardestani A, Hoffman HJ, Cooper HA (2010) Obesity and outcomes among patients with established atrial fibrillation. The American journal of cardiology 106(3): 369-373. 
(C) (P) This work is licensed under Creative

DOI: $10.32474 / A D 0.2019 .02 .000127$

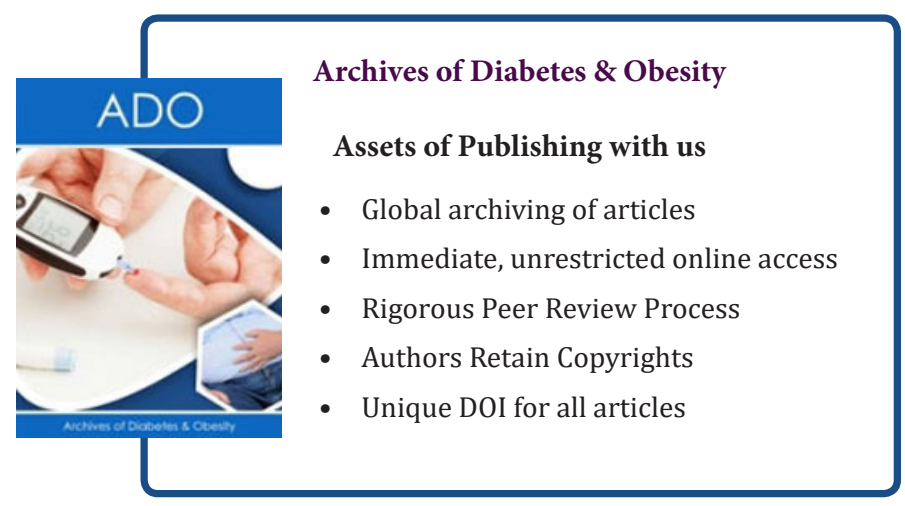

